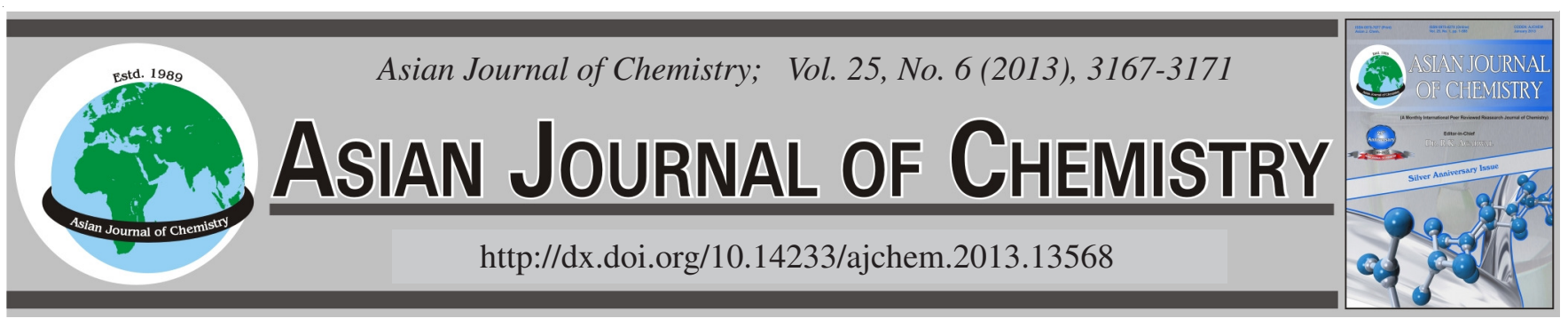

\title{
Sodium Dodecyl Benzene Sulfonate Modified Layered Double Hydroxides as a Photocatalyst Under Simulated Solar Radiation for Removal of Malachite Green
}

\author{
C.X. CHEN ${ }^{1,2}$, Y.C. Hou ${ }^{1}$, B. LI $^{1, *}$ and W.Z. YI ${ }^{1}$
}

${ }^{1}$ College of Science, Northeast Forestry University, Harbin 150040, P.R. China

${ }^{2}$ Post-Doctoral Mobile Research Station of Forestry Engineering, Northeast Forestry University, Harbin 150040, P.R. China

*Corresponding author: Tel: +86451 82190679; E-mail: ccx1759@163.com

(Received: 8 February 2012;

Accepted: 14 December 2012)

AJC-12541

\begin{abstract}
Sodium dodecyl benzene sulfonate modified layered double hydroxides (DBS-modified-LDHs) were prepared by low saturated state of coprecipitation with microwave assisted crystallization. The resulting samples were characterized by XRD, FT-IR, TEM and ICP-OES. The analytical results show that the as-produced DBS-modified-LDHs have good dispersibility while maintaining the structure of LDHs, indicating the use of microwave irradiation to speed up catalyst preparation is feasible. The formula of the DBS-modified-LDHs was calculated to be $\mathrm{Mg}_{2.85} \mathrm{Al}(\mathrm{OH})_{7.69}\left(\mathrm{CO}_{3}\right)_{0.46}(\mathrm{DBS})_{0.089} \cdot 2.88 \mathrm{H}_{2} \mathrm{O}$, which is in agreement with the FT-IR results. After calcination, the resulting sodium dodecyl benzene sulfonate modified layered double oxide (DBS-modified-LDO) was used for the decolourization of malachite green. The effects of malachite green concentration, catalyst loading and light intensity on decolourization efficiency were investigated. The total time required to decolourize malachite green was found to be $7.5 \mathrm{~min}$ in the presence of DBS-modified-LDO $\left(20 \mathrm{~g} \mathrm{~L}^{-1}\right)$ at $70{ }^{\circ} \mathrm{C}$ and irradiated under a light source (8400 Lux). In addition, used DBS-modified-LDO can be regenerated and the photocatalytic efficiency was stable even after 5 cycles without significant loss in decolourization activity. An average decolourization time of 14.3 min can be obtained during the cyclic process. The results suggest that DBS-modified-LDO can be used as a novel and efficient photocatalyst for the decolourization of malachite green.
\end{abstract}

Key Words: Layered double hydroxides, Dodecyl benzene sulfonate, Malachite green, Microwave irradiation, Photocatalyst.

\section{INTRODUCTION}

Malachite green, a triphenylmethane dye, is extensively used for the dyeing of textiles, silk, leather and paper, as well as in the manufacturing of paints and printing inks ${ }^{1}$. However, malachite green is a carcinogenic organic molecule and difficult to remove from aqueous solutions. Malachite green affects the aquatic life by causing detrimental effects in liver, gill, intestine, kidney, gonads and pituitary gonadotrophic cells when discharged into receiving streams $\mathrm{s}^{2,3}$. Therefore, there are both environmental and health concerns in relation to the use and proper disposal of this particular dye. Moreover, the removal of malachite green in wastewater is especially important. Among the many methods available for the removal of malachite green, adsorption is the most versatile technique for the removal of malachite green from aqueous solutions ${ }^{4}$. Many adsorbents have been tested to determine their potential to lower malachite green concentrations from aqueous solutions, such as activated carbon ${ }^{5,6}$, peat ${ }^{7,8}$, chitin ${ }^{9}$, silica ${ }^{10}$ and others ${ }^{4,11}$. However, the adsorption method only transfers malachite green to another material, but does not completely eliminate the harmful molecule from the environment. The photocatalytic decomposition of various organic compounds in industrial wastewater has been extensively studied, because pollutants can be quickly eradicated using this technique ${ }^{1,12-16}$. However, in spite of extensive research, most systems have shown insufficient practical efficiency.

Layered double hydroxides (LDHs) have attracted increasing attention from different fields in recent years due to their peculiar configuration and properties ${ }^{17-20}$. The chemical structure of layered double hydroxides is

$$
\left[\mathrm{M}_{1-\mathrm{x}}^{\mathrm{II}} \mathrm{M}_{\mathrm{x}}^{\mathrm{III}}(\mathrm{OH})_{2}\right]^{\mathrm{x}+}\left[\mathrm{X}^{\mathrm{m}-}\right]_{\mathrm{x} / \mathrm{m}} \cdot \mathrm{nH}_{2} \mathrm{O}
$$

wherein $\mathrm{M}^{\mathrm{II}}$ and $\mathrm{M}^{\mathrm{III}}$ represent divalent and trivalent metal ions, respectively, $\mathrm{X}^{\mathrm{m}-}$ represents the negative ions, $n$ is the amount of water in the crystal and $\mathrm{x}$ is the molar ratio of trivalent metal ions to all metal ions ${ }^{21}$. At present, some pioneering work $^{22-26}$ using layered double hydroxides or layered double oxide as photocatalysts have shown encouraging results. Whereas ordinary layered double hydroxides are chemically similar to water, printing dye pollutants are mostly organic ions or molecules. Therefore, in order to achieve compatibility, surface modification of layered double hydroxides is 
a worthy new field of research. Since dodecyl benzene sulfonate (DBS) is a good surfactant, in this study, DBS-modified-layered double hydroxides were prepared by a coprecipitation method under microwave irradiation for the removal of malachite green by photocatalytic degradation.

\section{EXPERIMENTAL}

Synthesis of DBS-modified-LDHs: An aqueous solution containing metal nitrates (such as $\mathrm{Mg}\left(\mathrm{NO}_{3}\right)_{2}$ and $\mathrm{Al}\left(\mathrm{NO}_{3}\right)_{3}$, the ratio of $\mathrm{Mg}^{2+}$ to $\mathrm{Al}^{3+}$ being 3) and a solution containing $1 \mathrm{M} \mathrm{NaOH}$ and saturated dodecyl benzene sulfonate were simultaneously titrated into a three necked round-bottom flask under vigorous stirring at $80^{\circ} \mathrm{C}$. The titration rates of the solutions were controlled in order to maintain the $\mathrm{pH}$ value of the mixture solution at about 9. After the titration, stirring was continued for $1 \mathrm{~h}$, at which time a heavy precursor gel was obtained and then crystallized at $70^{\circ} \mathrm{C}$ for 10 min under microwave irradiation in a domestic microwave oven (Midea KD23B-DA, the input and output power of $1300 \mathrm{~W}$ and $800 \mathrm{~W}$ and a frequency of $2.45 \mathrm{GHz}$ ). The precipitate was filtered, washed and dried to obtain DBS-modified-LDHs. All the chemicals used in the experimental work were analytical grade reagents.

Characterization of DBS-modified-LDHs: X-ray powder diffraction (XRD) data were recorded on a Japan Rigaku D/MAX 2200VPC X-ray diffractometer with $\mathrm{CuK}_{\alpha}$ radiation in the range of $5^{\circ} \leq 2 \theta \leq 75^{\circ}$. The FT-IR spectra were recorded on the AVATAR360 FT-IR (Nicolet Corporation, USA) in the range of $4000-500 \mathrm{~cm}^{-1}$ using the $\mathrm{KBr}$ pellet techniques. Transmission electron microscopy was performed on Hitachi-7650 electron microscope $(\mathrm{H}-7650)$ with the acceleration voltage of $100 \mathrm{kV}$ and amplifying multiple of ten thousand. Elemental chemical analyses for $\mathrm{Mg}, \mathrm{Al}$ and $\mathrm{S}$ were carried out in PerkinElmer Optima 5300 Dual-View ICP-OES plasm transmit spectrophotometer with an Elementar Vario EL III Cube.

Photocatalytic experiments: The photocatalytic experiments were carried out in a $100 \mathrm{~mL}$ beaker equipped with a magnetic stirrer as the reactor and a simulated solar lamp (LZG, China) was used as the irradiation source; the light intensity was measured with a digital LUX Meter (LX-1010B, China). The photocatalytic system was prepared by adding $3.0-30 \mathrm{mg}$ $\mathrm{L}^{-1}$ solution of malachite green and catalyst in water at the desired concentration. The total volume of the solution for the reaction was adjusted to $50 \mathrm{~mL}$.

\section{RESULTS AND DISCUSSION}

Effect of light intensity on decolourization of malachite green: The influence of light intensity on malachite green decolourization was examined at a constant initial malachite green concentration of $30 \mathrm{mg} \mathrm{L}^{-1}$ and catalyst loading of $20 \mathrm{~g}$ $\mathrm{L}^{-1}$. The relationship between the total decolourization time and light intensity is illustrated in Fig. 1. The light intensity was varied from 0 to 8400 Lux by changing the power of the lamps. It can be seen that the decolourization time gradually decreases with increasing light intensity, which indicates that light intensity plays a significant role in malachite green decolourization. This can be explained by the effect of photoexcitation, which produces mobility of charges in the lamellar structure and induces the formation of photoactive defects ${ }^{27}$.
Effect of malachite green concentration: The influence of malachite green initial concentration on the photocatalytic colour removal is important. As shown in Fig. 2, the effect of malachite green concentration on the decolourization efficiency was studied by varying the initial malachite green concentration (3.0-30 mg L $\mathrm{m}^{-1}$ ). All the other operating parameters were kept constant as follows: the DBS-modified-LDO concentration was $20 \mathrm{~g} \mathrm{~L}^{-1}$, the light intensity was $8400 \mathrm{Lux}$ and the reaction temperature was $70^{\circ} \mathrm{C}$. The results show that the decolourization time during the first stage increased sharply with increasing initial malachite green concentrations up to $30 \mathrm{mg} \mathrm{L}^{-1}$. In other words, the photocatalytic degradation efficiency of DBS-modified-LDO under simulated solar light was found to decrease with increasing concentration of malachite green from 3 to $30 \mathrm{mg} \mathrm{L}^{-1}$. This may be because as more malachite green molecules are adsorbed on the surface of DBSmodified-LDO, the electron acceptor in the photocatalysis will be reduced ${ }^{1,28,29}$. In addition, more malachite green will absorb much of the light required during the photocatalysis process and consequently lower the photodegradation efficiency ${ }^{29}$.

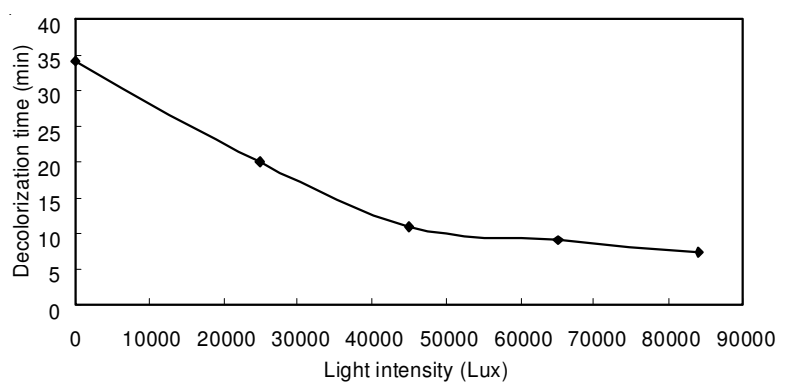

Fig. 1. Effect of light intensity on decolourization

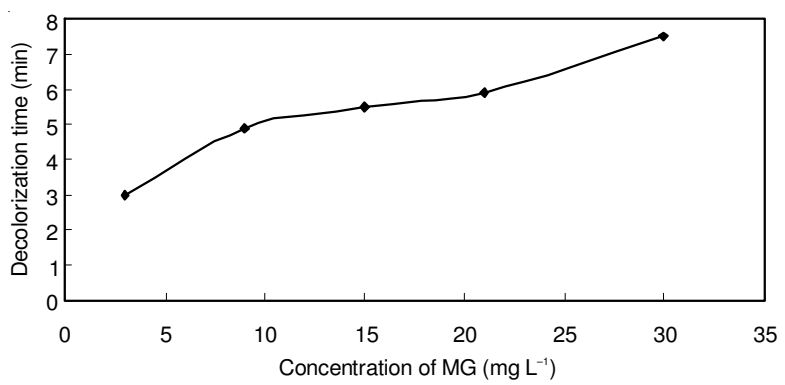

Fig. 2. Effect of initial concentration of malachite green on decolourization

Effect of DBS-modified-LDO loading: Catalyst loading is an important factor that can significantly influence the photocatalytic decolourization performance. To optimize catalyst loading, a series of experiments were carried out in which the DBS-modified-LDO concentration was varied from 0.2 to 20 $\mathrm{g} \mathrm{L}^{-1}$, while all other operating parameters were kept constant as follows: the malachite green concentration was $30 \mathrm{~g} \mathrm{~L}^{-1}$ and the reaction temperature was $70{ }^{\circ} \mathrm{C}$. The results are presented in Fig. 3. The entire decolourization time in the first stage decreased rapidly as the loading of DBS-modified-LDO was increased for $\mathrm{c}<2 \mathrm{~g} \mathrm{~L}^{-1}$. However, at higher loadings above $10 \mathrm{~g} \mathrm{~L}^{-1}$, the entire decolourization time approaches a constant value, suggesting that an optimal level for catalyst effectiveness exists. The results also indicate that the photocatalytic efficiency increases up to a maximum catalyst loading and tends to decrease upon further loading. The increase 
in malachite green degradation as the catalyst loading was increased from 0 to $2 \mathrm{~g} \mathrm{~L}^{-1}$ was due to the increase in the availability of active sites on the catalyst surface at which malachite green can be adsorbed. However, as the optimal catalyst loading was reached, the degradation efficiency remained almost constant with increased catalyst loading from 2 to $20 \mathrm{~g} \mathrm{~L}^{-1}$. Hence, loading above $2 \mathrm{~g} \mathrm{~L}^{-1}$ did not markedly increase the degradation efficiency any further. This phenomenon may be due to the aggregation of a high concentration of catalyst, which can reduce the total active surface area available for adsorbing malachite green ${ }^{30,31}$. Therefore, the optimal amount of catalyst is $2 \mathrm{~g} \mathrm{~L}^{-1}$ for the decolourization of malachite green at a concentration of $30 \mathrm{mg} \mathrm{L}^{-1}$.

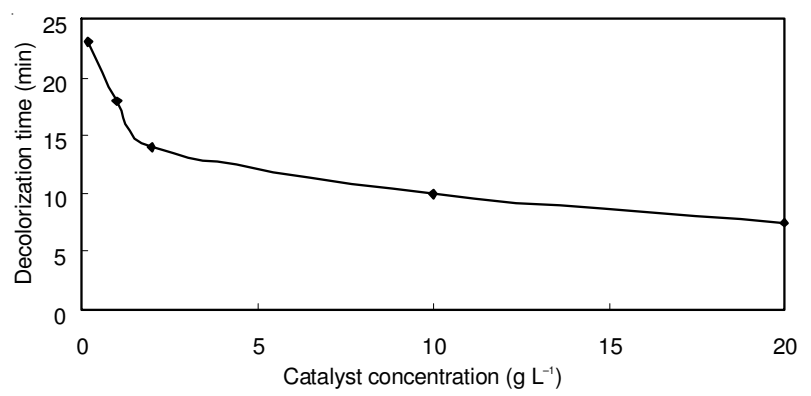

Fig. 3. Effect of catalyst loading on decolourization

Cycle lifetime of DBS-modified-LDO: The cycle lifetime of catalysts is always a concern in many industrial catalytic processes. The cycle lifetime of DBS-modified-LDO in the malachite green decolourization process was investigated under the following conditions. The DBS-modified-LDO concentration was $\mathrm{C}_{\text {Cat. }}=20 \mathrm{~g} \mathrm{~L}^{-1}$, light intensity was 8400 Lux and the reaction temperature was $70^{\circ} \mathrm{C}$. The results shows that the entire decolourization time exhibited little change in the reaction catalyzed by DBS-modified-LDO (Fig. 4). Furthermore, the fifth cycle took only $25 \mathrm{~min}$. The photocatalytic efficiency is stable after 5 usages without significant loss of decolourization activity and the average total decolourization time of 14.3 min can be obtained, implying that DBS-modifiedLDO is effectively reusable. This may be because the DBSmodified-LDO has a high specific surface area which can recover its layered structure by simple contact with the aqueous solution of malachite green. The ability of the layered double hydroxides' memory effect to regenerate after moderate heating is thought to be one of its most interesting and useful proper$\operatorname{ties}^{32}$. Therefore, DBS-modified-LDO would be a promising and reusable photocatalyst for malachite green decolourization.

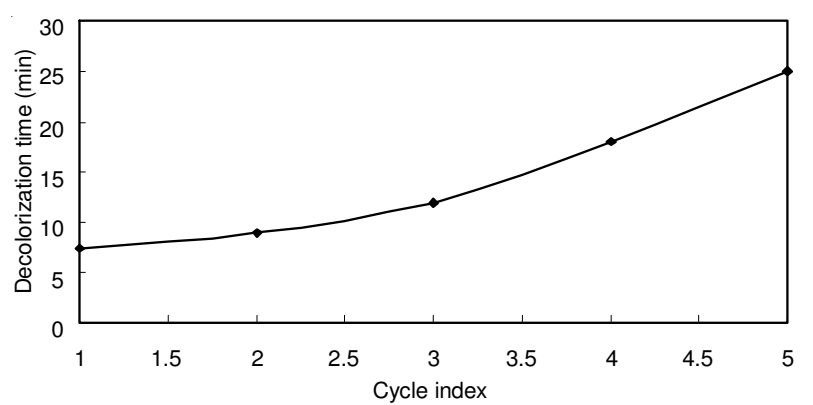

Fig. 4. Cycle lifetime of DBS-modified-LDO in the decolourization of malachite green
Characterization: The raw material ratio of $\mathrm{n}\left(\mathrm{Mg}^{2+}\right)$ : $\mathrm{n}\left(\mathrm{Al}^{3+}\right)$ is 3:1 for DBS-modified-LDHs. The elemental analysis was carried out using a plasma transmit spectrophotometer and the results are as follows: $\mathrm{Mg} 23.28 \%, \mathrm{Al} 9.02 \%, \mathrm{~S} 0.97 \%$. According to the general formula ${ }^{33}$ and charge conservation for the layered double hydroxides, the content of other elements can be calculated. Therefore, we can obtain the structure formula of the prepared DBS-modified-LDHs as being $\mathrm{Mg}_{2.85} \mathrm{Al}(\mathrm{OH})_{7.69}\left(\mathrm{CO}_{3}\right)_{0.46}(\mathrm{DBS})_{0.089} \cdot 2.88 \mathrm{H}_{2} \mathrm{O}$.

The structures of the prepared samples were characterized by XRD technique. As shown in Fig. 5, the XRD patterns of samples $A$ and $C$ exhibited the typical reflection at $2 \theta=11.3$, $22.6,34.5,60.7^{\circ}$, which are almost identical to the typical pattern characteristic of layered double hydroxides phase as previously reported ${ }^{34,35}$. These reflection peaks are ascribed to the diffraction by basal planes (003), (006), (009), (110), respectively. Moreover, the XRDs of samples B and D are very similar, which indicates that the DBS-modified-LDOs can regenerate the layered structure by simple contact with the aqueous malachite green solution ${ }^{36}$. Although LDOs are not semiconducting materials, their high photo-assist activity was surprising. This degradation may be caused by the adsorption by LDO or reconstruction effect as shown in Fig. 5 (sample C).

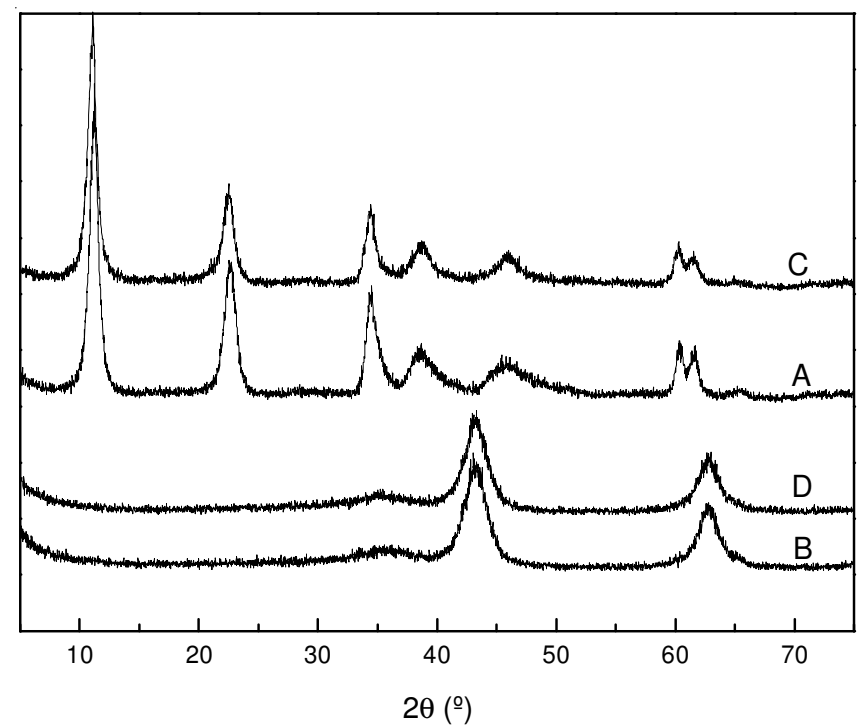

Fig. 5. XRD patterns of the prepared samples; A: Freshly prepared DBSmodified-LDHs; B: Fresh DBS-modified-LDO (DBS-modifiedLDHs calcined at $400{ }^{\circ} \mathrm{C}$ for $4 \mathrm{~h}$ ); C: Used DBS-modified-LDO (used once); D: Sample C regenerated by calcination at $400{ }^{\circ} \mathrm{C}$ for $4 \mathrm{~h}$

FT-IR spectra were collected to determine the structure of the DBS-modified-LDHs and whether dodecyl benzene sulfonate was doped into the layered double hydroxides. As shown in Fig. 6, the band centered at around $3510 \mathrm{~cm}^{-1}$ is attributed to the $\mathrm{V}_{\mathrm{OH}^{-}}$-stretching mode of hydroxyl groups from water molecules in the layers and interlayer of layered double hydroxides. The band at $1638 \mathrm{~cm}^{-1}$ is attributed to the combination stretch vibration of $\mathrm{C}-\mathrm{C}$ and $\mathrm{C}=\mathrm{C}$, while the band at $644 \mathrm{~cm}^{-1}$ can be ascribed to the out plane bound vibration of $\mathrm{C}-\mathrm{H}$. The bands at $1116 \mathrm{~cm}^{-1}$ are attributed to the $\mathrm{S}=\mathrm{O}$ stretch vibration characteristic of dodecyl benzene sulfonate ${ }^{37}$. In 
addition, the sharp band at $1373 \mathrm{~cm}^{-1}$ demonstrates the presence of a certain amount of interlayer carbonate ions. This is due to contamination resulted from the absorption of atmospheric $\mathrm{CO}_{2}$ under unavoidable conditions of microwave crystallization and washing ${ }^{38}$. Namely, the dodecyl benzene sulfonate anions and a portion of carbonate are intercalated into the layered double hydroxides, which is in agreement with the elemental analysis. The FT-IR spectrum of sample $\mathrm{C}$ shows characteristic absorption peaks at $3510 \mathrm{~cm}^{-1}$ and $1373 \mathrm{~cm}^{-1}$, which are almost identical to the carbonate intercalated layered double hydroxides. This implies that DBS-modifiedLDO is able to recover the layered structure by simple contact with aqueous solution of malachite green. However, the exchange of anions is not with malachite green but rather with the carbonate as illustrated by the FT-IR comparison between samples B and C. Interestingly, after the decolourization was complete, malachite green was not observed on the DBSmodified-LDO catalyst surface nor was it detected in the water solution by IR characterization. It is possible that malachite green has been degraded by the DBS-modified-LDO under simulated sunlight conditions.

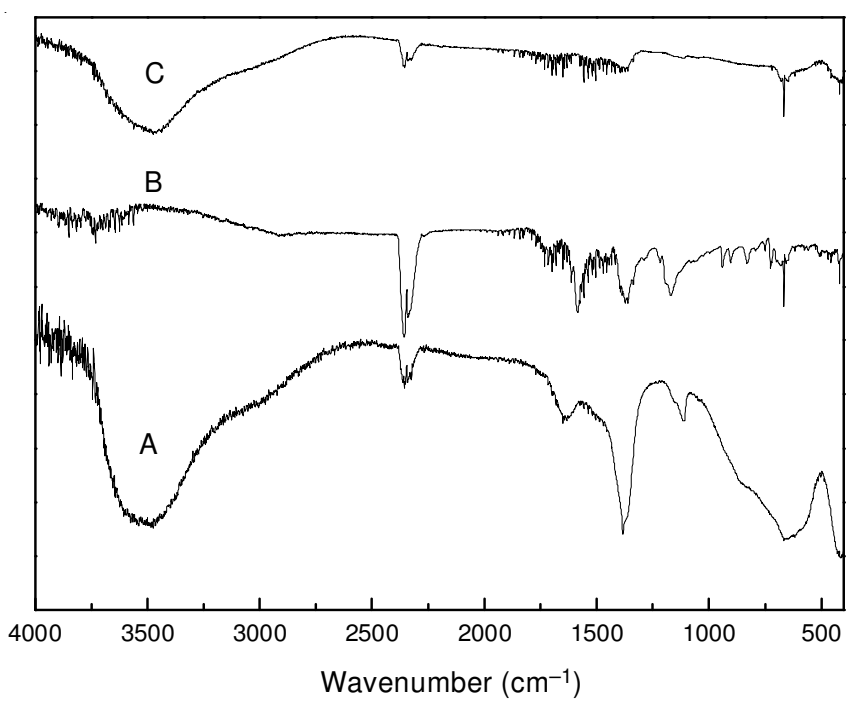

Fig. 6. IR spectra overlay of the prepared samples; A: Fresh DBS-modifiedLDHs; B: malachite green; C: Used DBS-modified-LDO (used once)

TEM images of treated samples are shown in Fig. 7. It can be seen that ideal nano-DBS-modified-LDHs particles can be synthesized under microwave conditions to give hexagonal particles with good dispersion and a narrow particle size ranging from 30 to $60 \mathrm{~nm}$ (Fig. 7, image A). Furthermore, the microwave assisted synthesis requires a short crystallization time of $10 \mathrm{~min}$ in comparison with the conventional crystallization time of $15 \mathrm{~h}$. The microwave irradiation method saves time and energy, making it an ideal method for synthesizing nano-materials. As shown in image B, DBS-modified-LDHs calcined at $400{ }^{\circ} \mathrm{C}$ for $4 \mathrm{~h}$ (DBS-modified-LDOs) are spherical particles. From the TEM image, it is obvious that the dispersion of sample C (DBS-modified-LDO used once) is much worse than that of $\mathrm{A}$ (the fresh sample), indicating that $\mathrm{C}$ has been fouled to a certain degree after the treatment, which weakened the hexagonal structure of the layered double hydroxides. However, spherical particles can be seen (image D) after heating at $400{ }^{\circ} \mathrm{C}$ for $4 \mathrm{~h}$, which indicates that the spent DBS-modified-LDO can be regenerated to give high quantities of active surface species and be reused ${ }^{32}$.

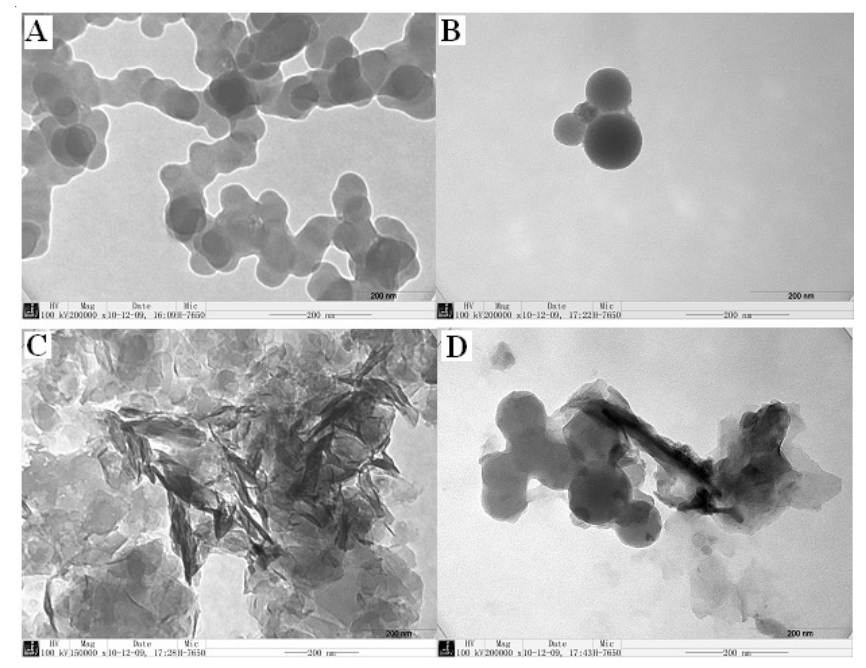

Fig. 7. TEM images of the prepared samples

\section{Conclusion}

We have investigated the use of sodiumdodecyl benzene sulfonate-modified-layered double oxide as a photocatalyst for the removal and decolourization of malachite green in aqueous solutions. Present results showed that almost complete decolourization can be achieved over a short period of irradiation. The total decolourization time was only $7.5 \mathrm{~min}$ in the presence of DBS-modified-LDO photocatalyst when the reaction was carried out at $70{ }^{\circ} \mathrm{C}$, catalyst loading of $20 \mathrm{~g} \mathrm{~L}^{-1}$ and a light intensity of 8400 Lux. As the malachite green concentration was increased from 3 to $30 \mathrm{mg} \mathrm{L}^{-1}$, the decolourization time was increased from 3 to $7.5 \mathrm{~min}$. In addition to the easy preparation by microwave irradiation, the catalyst can be separated from the reaction mixture and recycled by heating at $400{ }^{\circ} \mathrm{C}$ for $4 \mathrm{~h}$. The XRD, FT-IR and TEM results showed that the as-produced DBS-modified-LDH samples have good dispersibility and retained the structure of layered double hydroxides, while the DBS-modified-LDO are able to recover the layered structure and generate a high quantity of photocatalytic decolourization activity. Therefore, DBS-modifiedLDO have great potential to be promising photocatalyst candidates that offer environmentally benign photocatalytic decolourization of malachite green.

\section{ACKNOWLEDGEMENTS}

The investigation was supported by the Fundamental Research Funds for the Central Universities (No. DL11CB06) and China Postdoctoral Science Foundation (No. 20100480955).

\section{REFERENCES}

1. Y.G. Liu, Y. Ohko, R.Q. Zhang, Y.N. Yang and Z.Y. Zhang, J. Hazard. Mater., 184, 386 (2010).

2. S. Srivastava, R. Sinha and D. Roy, Aquat. Toxicol., 66, 319 (2004).

3. B.H. Hameed and T.W. Lee, J. Hazard. Mater., 164, 468 (2009).

4. S.S. Tahir and N. Rauf, Chemosphere, 63, 1842 (2006).

5. K.V.K. Rao, Toxicol. Lett., 81, 107 (1995).

6. L.G. Rushing and E.B. Hansen Jr., J. Chromatogr. B, 700, 223 (1997). 
7. Y.S. Ho and G. McKay, Chem. Eng. J., 70, 115 (1998).

8. K.R. Ramakrishna and T. Viraraghavan, Water Sci. Technol., 36, 189 (1997).

9. R.J. Shukla and A. Singh, Asian J. Chem., 11, 259 (1999).

10. G. McKay, AIChE J., 30, 692 (1984).

11. Z. Bekçi, C. Ozveri, Y. Seki and K. Yurdakoç, J. Hazard. Mater., 154, 254 (2008).

12. M. Farooq, I.A. Raja and A. Pervez, Sol. Energy, 83, 1527 (2009).

13. A.A. Ismail, Appl. Catal. B: Environ., 85, 33 (2008).

14. S.K. Mohapatra, N. Kondamudi, S. Banerjee and M. Misra, Langmuir, 24, 11276 (2008).

15. S.K. Pardeshi and A.B. Patil, Sol. Energy, 82, 700 (2008)

16. H. Tian, J.F. Ma, K. Li and J.J. Li, Mater. Chem. Phys., 112, 47 (2008),

17. K. Kaneda, S. Ueno and T. Imanaka, J. Mol. Catal. A: Chem., 102, 135 (1995).

18. A. Vaccari, Catal. Today, 41, 53 (1998).

19. S. Kannan, A. Dubey and H. Knozinger, J. Catal., 231, 381 (2005).

20. C.X. Chen, C.H. Xu, L.R. Feng, J.S. Suo and F.L. Qiu, Chem. Lett., 34, 206 (2005)

21. Y.J. Feng, D.Q. Li, C.X. Li, Z.H. Wang, D.G. Evang and X. Duan, Acta Chimica Sinica, 61, 78 (2003).

22. Y.F. Zhao, M. Wei, J. Lu, Z.L. Wang and X. Duan, ACS Nano, 3, 4009 (2009).

23. Y. Zhi, Y. Li, Q. Zhang and H. Wang, Langmuir, 26, 15546 (2010).

24. J.S. Valente, F. Tzompantzi and J. Prince, Appl. Catal. B, 102, 276 (2011).

25. S.C. Gomes, Y. Bouizi, V. Fornés and H. García, J. Am. Chem. Soc., 131, 13833 (2009).
26. Y.F. Zhao, S. He, M. Wei, D.G. Evans and X. Duan, Chem. Commun., 46, 3031 (2010).

27. A. Mantilla, G. Jacome-Acatitla, G. Morales-Mendoza, F. Tzompantzi and R. Gomez, Ind. Eng. Chem. Res., 50, 2762 (2011).

28. C.S. Lu, Y.T. Wu, F.D. Mai, W.S. Chung, C.W. Wu, W.Y. Lin and C.C. Chen, J. Mol. Catal. A: Chem., 310, 159 (2009).

29. M.A. Rauf and S.S. Ashraf, Chem. Eng. J., 151, 10 (2009).

30. B. Neppolian, H.C. Choi, S. Sakthivel, B. Arabindoo and V. Murugesan, Chemosphere, 46, 1173 (2002).

31. S. Sakthivel, B. Neppolian, M.V. Shankar, B. Arabindoo, M. Palanichamy and V. Murugesan, Solar Energy Mater. Solar Cells, 77, 65 (2003).

32. C. Gennequin, T. Barakat, H.L. Tidahy, R. Cousin, J.-F. Lamonier, A. Aboukaïs and S. Siffert, Catal. Today, 157, 191 (2010).

33. E.C. Kruissink, H.L. Pelt, J.R.H. Ross and L.L. van Reijen, App. Catal., 1, 23 (1981).

34. F. Kooli, K. Kosuge and A. Tsunashima, J. Solid State Chem., 118, 285 (1995)

35. P. Courty, D. Durand, E. Freund and A. Sugier, J. Mol. Catal., 17, 241 (1982).

36. D.P. Debecker, E.M. Gaigneaux and G. Busca, Exploring, Chem. Eur. J., 15, 3920 (2009).

37. M.L. Liu, Y.Y. Zhang, M.L. Wang, C.Y. Deng, Q.J. Xie and S.Z. Yao, Polymer, 47, 3372 (2006).

38. L. Du and B. Qu, J. Mater. Chem., 16, 1549 (2006). 